\title{
Dirty Downstream Ganges: What Fate is Waiting?
}

\author{
Abhijit Mitra* \\ Department of Marine Science, University of Calcutta, 35, B. C. Road, Kolkata-700 019, India
}

Received: August 15, 2016; Accepted: September 19, 2016; Published: September 21, 2016

*Corresponding author: Abhijit Mitra, Department of Marine Science, University of Calcutta, 35, B. C. Road, Kolkata-700 019, India, E-mail: abhijit_mitra@hotmail.com

The Hugli estuary, in the extreme western part of the lower Gangetic delta in the downstream region is a major estuary of the tropics. It is adjacent to the highly urbanized city of Kolkata, Howrah and the newly emerging Haldia port-cum-industrial complex. The selected sampling station (marked in yellow square) is $2.8 \mathrm{~km}$ off Sagar island (the triangular big island on the middle of the map), which is almost at the confluence of the Hugli estuary and the Bay of Bengal (Figure 1). This area has been selected as the test bed of the present study owing (i) presence of multifarious industries that are the point sources of zinc, copper and lead (ii) continuous plying of fishing vessels and trawlers that use antifouling paints for conditioning, whose main ingredients are zinc, copper and lead (non-point sources) (iii) presence of brick kilns, industries and thickly populated city of Kolkata, Howrah and the Haldia port-cum-industrial complex that serve as the primary sources of carbon dioxide at the local level and (iv) a major navigational channel in the region.

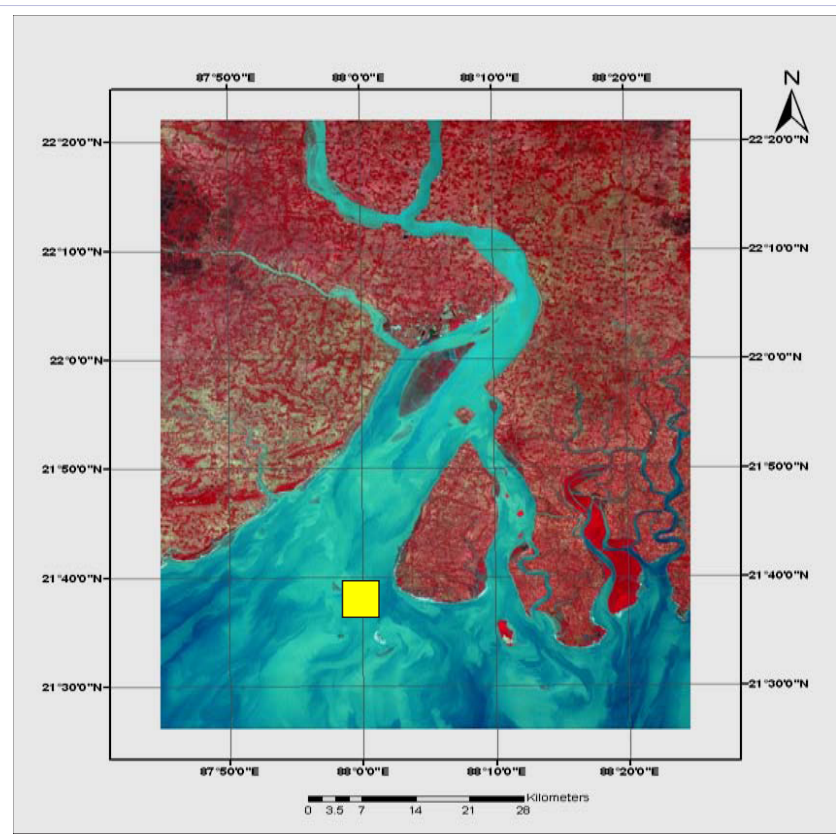

Figure 1: Sampling station (marked in yellow square) in the Hugli estuary

\section{Data Bank}

A number of studies on different aspects of the lower Gangetic delta complex have been published over the years, which include description of the data (and methods) at different times over the past three decades [1-10]. Real time data were also collected simultaneously since 1998 from the sampling site during high tide condition to assure quality and continuity to the data bank. Finally time series analysis was performed to forecast the trend of selected variables on the basis of the past 30 years' realtime data. Exponential smoothing method produces maximum likelihood estimates and can reflect the future trend of the selected variables. This approach was used to forecast the values for aquatic $\mathrm{pH}$ and selected heavy metals $(\mathrm{Zn}, \mathrm{Cu}$ and $\mathrm{Pb}$ ) in the ambient media of the sampling station till 2043. Predictions of the selected variables were carried out (using statistical models) to see the future of the region after 30 years.

\section{Gangetic Delta Water: Present and Future Surface water $\mathbf{p H}$}

The surface water $\mathrm{pH}$ exhibited variation within a small range. The lowest and highest pH values were 8.27 (in 2013) and 8.34 (in 1984) respectively (Figure 2). The forecast method predicts the pH value to be 8.28 during 2043 (Figure 3).

\section{Dissolved metal}

The order of dissolved heavy metals in the estuarine water is zinc > copper > lead. In the selected station, zinc ranged from $234.29 \mathrm{ppm}$ (in 1984) to $501.90 \mathrm{ppm}$ (in 2013) (Figure 4), dissolved Copper ranged from $50.95 \mathrm{ppm}$ (in 1984) to 264.00 ppm (in 2013) (Figure 5) and dissolved lead ranged from $8.59 \mathrm{ppm}$ (in 1984) to $43.83 \mathrm{ppm}$ (in 2013) (Figure 6). All the dissolved metals exhibit an increasing trend. It is also predicted that dissolved zinc, copper and lead will touch 698.98 ppb 497.65 $\mathrm{ppb}$ and $76.60 \mathrm{ppb}$ respectively after a period of 30 years (Figures $7,8,9)$.

\section{Biologically Available Sediment (BAS) metal}

In the sediment compartment, the biologically available heavy metals exhibited a decreasing trend with time. During the 


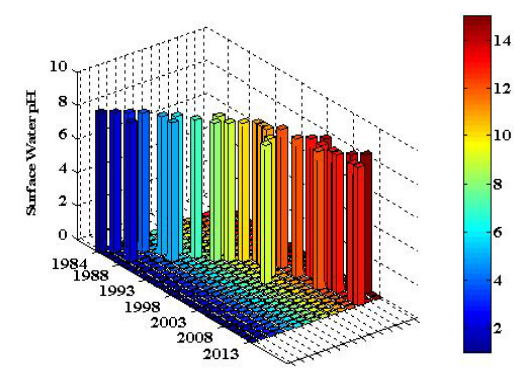

Figure 2: Temporal variation of surface water $\mathrm{pH}$.

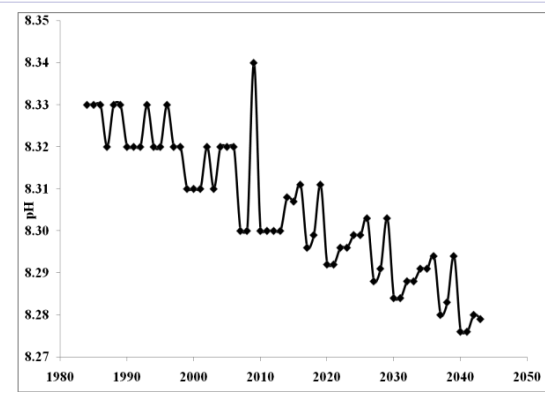

Figure 3: Forecast values of surface water $\mathrm{pH}$.

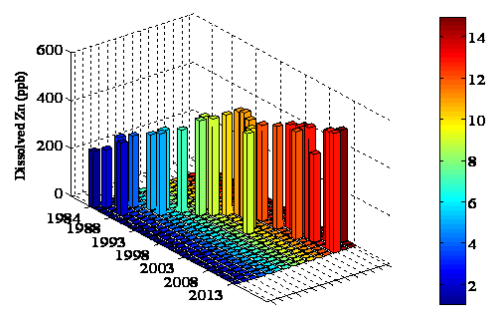

Figure 4: Temporal variation of dissolved Zinc.

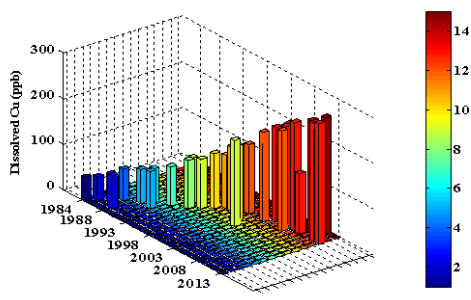

Figure 5: Temporal variation of dissolved Copper.

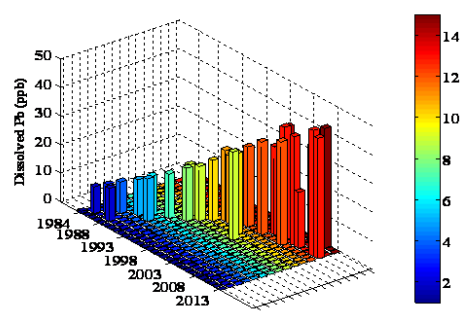

Figure 6: Temporal variation of dissolved Lead.

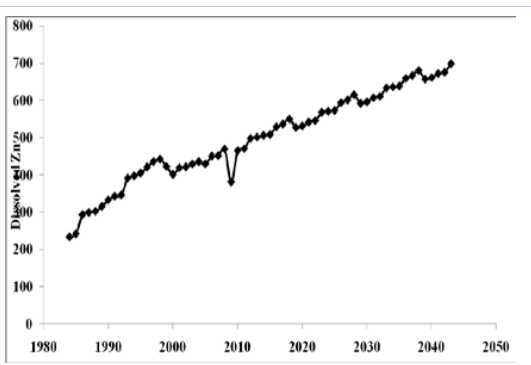

Figure 7: Forecast values of dissolved zinc.

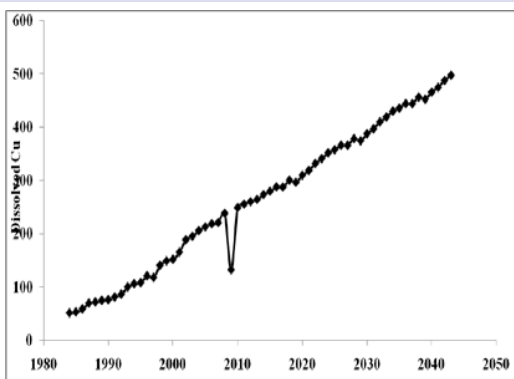

Figure 8: Forecast values of dissolved copper.

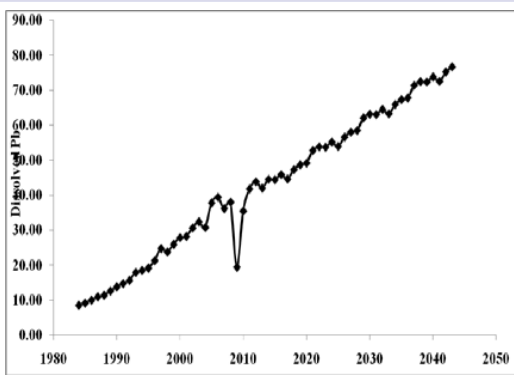

Figure 9: Forecast values of dissolved lead.

study span of 30 years, the values of zinc decreased from 92.75 ppm (in 1984) to 42.44 ppm (in 2013) (Figure 10). For copper, the values decreased from $32.49 \mathrm{ppm}$ (in 1984) to $12.05 \mathrm{ppm}$ (in 2013) (Figure 11) and for lead, the values decreased from $20.47 \mathrm{ppm}$ (in 1984) to $3.88 \mathrm{ppm}$ (in 2013) (Figure 12). It is also predicted that the values will touch $7.63 \mathrm{ppm}$ for biologically available sediment zinc and practically nil for both copper and lead during 2043 (Figures 13, 14, 15).

\section{Climate Induced Dirtiness?}

In the marine and estuarine compartments, heavy metals originate from both natural and anthropogenic sources. It is to be noted in this context that the industrial sources of heavy metals have not increased during the last two decades in the region, but the concentrations of dissolved heavy metals have increased substantially in the estuarine system. This can be confirmed from the industrial scenario around the study region, where the diversity and production volume of the industry have not increased substantially since last three decades. Interestingly the same metals have significantly decreased in the surface sediment compartment. After carefully scanning the health card 


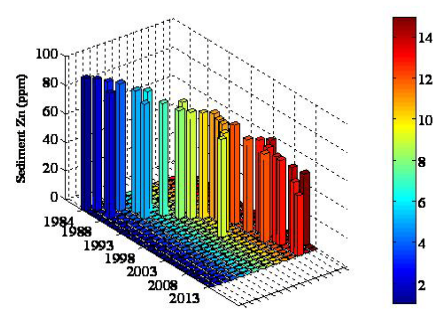

Figure10: Temporal variation of sediment zinc.

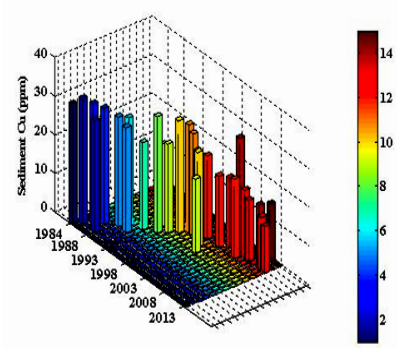

Figure11: Temporal variation of sediment copper.

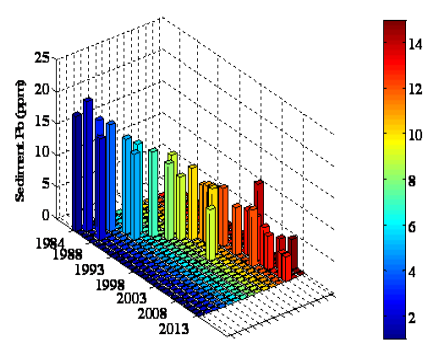

Figure12: Temporal variation of sediment lead.

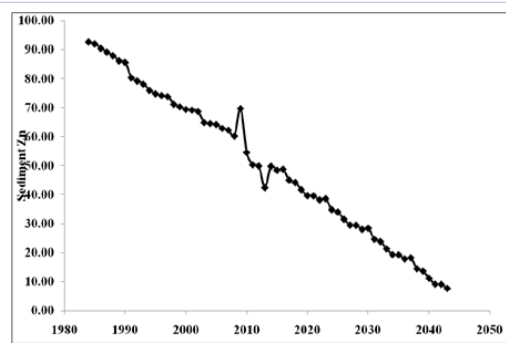

Figure13: Forecast values of sediment zinc.

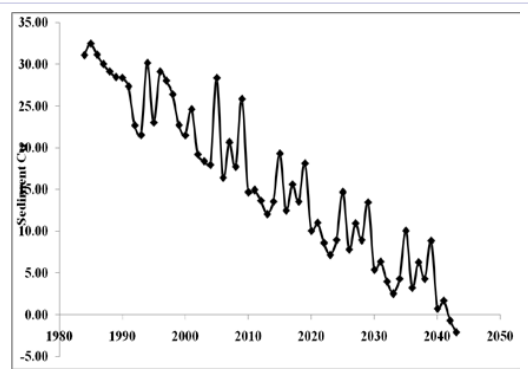

Figure 14: Forecast values of sediment Copper.

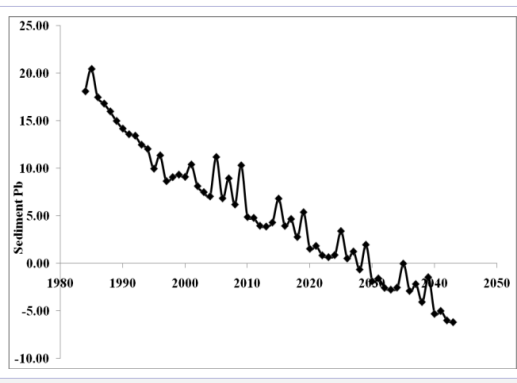

Figure 15: Forecast values of sediment lead.

of downstream Ganga water. The aquatic $\mathrm{pH}$, however, decreased as seen from the present data set, and thus it can be confirmed that acidification of estuarine water is a plausible reason of dissolution of heavy metals from the sediment compartment to the aquatic phase as evidenced by the significant inverse relationships between the respective dissolved and biologically available heavy metals in sediment. The aquatic $\mathrm{pH}$ is the main player behind the transference of heavy metals from the underlying sediment to overlying water column.

\section{Requirement for a Policy Change}

Till date, the Gangetic water monitoring programme never considered the natural forcing of climate related phenomena in the management action plan. The present article with long term scientific data and figures clearly points out the inclusion of climate change related events (preferably acidification) while developing the management policy for ecosystem restoration.

\section{References}

1. Chakraborty SK, Choudhury A. Distribution of fiddler crabs in Sundarbans mangrove estuarine complex, India. Proceedings of National Symposium on Biology, Utilization and Conservation of Mangroves. 1985;467-472.

2. Mitra A, Ghosh PB, Choudhury A. A marine bivalve Crassostrea cucullata can be used as an indicator species of marine pollution. Proceedings of National Seminar on Estuarine Management. 1987;177-180.

3. Mitra A, Choudhury A. Heavy metal concentrations in oyster Crassostrea cucullata of Henry's Island, India. Journal of Eco-biology. 1994;6(2):157-159.

4. Saha SB, Mitra A, Bhattacharyya SB, Choudhury A. Heavy metal pollution in Jagannath canal, an important tidal water body of the north Sundarbans aquatic ecosystem of West Bengal. Indian Journal of Environmental Protection. 1999; 801-804.

5. Banerjee K, Mitra A, Bhattacharyya DP, Choudhury A. Role of nutrients on phytoplankton diversity in the north-east coast of the Bay of Bengal. In: Ecology and Ethology of Aquatic Biota; (ed. Arvind Kumar), Daya Publishing House. 2002;102-109.

6. Banerjee K, Mitra A, Bhattacharyya DP. Phytopigment level of the aquatic subsystem of Indian Sundarbans at the apex of Bay of Bengal. Sea Explorers. 2003;6:39-46.

7. Mukhopadhyay SK, Biswas H, De TK, Jana TK. Fluxes of nutrients from the tropical River Hooghly at the land-ocean boundary of Sundarbans, NE Coast of Bay of Bengal, India. Journal of Marine Systems. 2006;62(1-2):9-21. 
8. Mitra A, Banerjee K, Sengupta K, Gangopadhyay A. Pulse of climate change in Indian Sundarbans: a myth or reality. National Academy of Science Letters. 2009;32:19-25.

9. Banerjee K, Sengupta K, Raha A, Mitra A. Salinity based allometric equations for biomass estimation of Sundarban mangroves. Biomass and Bioenergy. 2013;56:382-391.

10. Sengupta K, Roy Chowdhury M, Bhattacharya SB, Raha A, Zaman S, Mitra A. Spatial variation of stored carbon in Avicennia alba of Indian Sundarbans. Discovery Nature. 2013;3(8):19-24. 